\title{
Estimation of Volatile Organic Compounds (VOCs) and Human Health Risk Assessment of Simulated Indoor Environment Consisting of Upholstered Furniture Made of Commercially Available Foams
}

\author{
Alena Capíková, ${ }^{1}$ Daniela Tesařová, ${ }^{2}$ Josef Hlavaty, ${ }^{2}$ Adam Ekielski, ${ }^{3}$ \\ and Pawan Kumar Mishra ${ }^{4}{ }^{4}$ \\ ${ }^{1}$ Textile Testing Institute, Brno, Czech Republic \\ ${ }^{2}$ Department of Furniture, Design, and Habitat, Mendel University in Brno, Zemědělská 1665/1, 61300 Brno-sever-Černá Pole, \\ Brno, Czech Republic \\ ${ }^{3}$ Department of Production Management and Engineering, Warsaw University of Life Sciences, Warsaw, Poland \\ ${ }^{4}$ Department of Wood Processing Technology, Mendel University in Brno, Zemědělská 1665/1, 61300 Brno-sever-Černá Pole, Brno, \\ Czech Republic
}

Correspondence should be addressed to Pawan Kumar Mishra; xmishra@mendelu.cz

Received 25 April 2019; Accepted 31 July 2019; Published 9 October 2019

Guest Editor: Bin Xu

Copyright (C) 2019 Alena Capíková et al. This is an open access article distributed under the Creative Commons Attribution License, which permits unrestricted use, distribution, and reproduction in any medium, provided the original work is properly cited.

\begin{abstract}
This study was conducted for the qualitative and quantitative determination of volatile organic compounds (VOCs) and total volatile organic compounds (TVOC) from polymeric foam materials used in upholstered furniture. Six different types of foams viz. Highly elastic foam K5040, standard PU foam N5063, bonded polyurethane foam R100, viscoelastic foam V5020, self-extinguishing foam KF5560, and foam rubber were used. Short-term and long-term (24, 48, 72, 672 hours (28 day)) measurements were done to differentiate the role of primary emissions (present in new products) and secondary emissions (due to chemical reactions in material or slowly released due to the porous structure of material). The samples were collected using a small-space sampling chamber at a temperature of $23^{\circ} \mathrm{C}$ and a humidity of $50 \%$ depending on the aspect of time. The concentrations of VOC and TVOC were identified and quantified using a Gas chromatography-Mass spectroscopy (GC-MS) based method. Based on the VOC measurements, the standard room concentrations were simulated to estimate the human health risk assessment for all six types of foams. The results of simulations suggest no possibility of human health risk for the very long period ( 28 days), as the estimated values were found to be much below the prescribed limits.
\end{abstract}

\section{Introduction}

Today's society spends the majority of their time in confined spaces, mostly in their homes, up to $95 \%$ and about $6 \%$ of their time in vehicles [1]. The indoor environment is, therefore, an important aspect of human life, and it is essential that its quality - health safety-is at the highest level. Air quality can be measured and analyzed by taking an air sample, which is evaluated by the appropriate method for the amount of volatile organic substances (VOC) and total volatile organic compounds (TVOC) ranging from hexane to hexadecane (C6-C16) which is an indicator of ambient air cleanliness. The primary sources of emissions in the interior are furniture materials like the wood used in furniture [2, 3], foams, and human activities. The most widespread compounds are formaldehyde and acetaldehyde. The reason for their wide occurrence is their volatile character and the fact that they are widely used in the production of a large number of household products such as paints, lacquers, waxes, solvents, and detergents. They have also been shown to be emitted during the use of electronic devices such as printers, copiers, and others [4]. Concerns about consumer safety are a reason to control airborne pollutants like VOCs, and these undesirable substances are released from the materials used in indoor products manufacturing [5]. Several technologies have been developed to address this issue [6]. There are several other polymers like lignin and cellulose (in wood), and their 
TABLE 1: Parameters of various samples used in the study.

\begin{tabular}{lccc}
\hline Material & Density $\left(\mathrm{kg} \mathrm{m}^{-3}\right)$ & Cell diameter & Manufacturer and supplier \\
\hline Highly elastic foam K5040 & $46.5-51.5$ & $3 \mathrm{~mm}$ & Eurofoam GmbH (Austria) and BPP spol s.r.o, Czech Republic \\
Standard PU foam N5063 & $46.5-51.5$ & $0.8-1.5 \mathrm{~mm}$ & Eurofoam GmbH (Austria) and BPP spol s.r.o., Czech Republic \\
Bonded polyurethane foam R 100 & $90-120$ & - & Eurofoam GmbH (Austria) and BPP spol s.r.o, Czech Republic \\
Viscoelastic foam V5020 & $45-55$ & - & Eurofoam GmbH (Austria) and BPP spol s.r.o, Czech Republic \\
Self-extinguishing foam KF5560 & $51.5-59.5$ & - & Eurofoam GmbH (Austria) and BPP spol s.r.o, Czech Republic \\
Foam rubber & - & - & Eurofoam GmbH (Austria) and BPP spol s.r.o., Czech Republic \\
\hline
\end{tabular}

derivatives present in different indoor product formulations that can adsorb and retain the VOCs, but this study is more focused on upholstered furniture [7-10].

On average, one-third life of a person is spent by sleeping [11]. This is the time spent not only in bed but also on resting furniture such as upholstered sofas, where the lying area (seating area) is composed of foamed materials (called as polyurethane foams (PU) or foam rubber (LATEX name). These polymer-based materials have a cellular structure and are therefore porous and hence, to a certain extent, breathable. It performs the softening function of the touch surfaces with the body of the user, and at the same time, it can behave as a carrier of VOCs. Generally, VOCs can be controlled at source (during the manufacturing of the indoor product), ventilation, and air-cleaning [12]. The reported methods for air-cleaning include botanical purification, Catalytic combustion, Membrane Separation, Zeolite based adsorption, Bio-filtration, Absorption, and activated carbon-based adsorption [13-15]. Every method has its advantages and disadvantages, and the best suitable method can vary from site to site. In the context of upholstered furniture, properties of foam can be modified by additives, novel blowing agents and new biobased polymers or at least minimised within prescribed limits $[16,17]$.

In a previous study, the potential risks of VOCs released from five types of polyurethane foams by simulating the scenario of a man lying on a soft foam mattress for $8 \mathrm{~h} /$ day were estimated [18], in which, the measurements for very long-term intervals were missing that limited the data availability about passive emissions. In this study, six commonly used foams in upholstered furniture (commercially available) were characterized for their permeability and emitted VOCs. Measurements were done at the interval of $24,48,72$, and $672 \mathrm{~h}$ (28 days) intervals. Long-term measurements (28 days) were done to differentiate the primary emissions (physically released compounds present in new products) and secondary emissions (compounds produced by a chemical reaction in a product or in the microstructure and are released gradually). This study aims to provide the missing data about secondary emissions that take relatively long time to be emitted. Based on VOC values from our experiment, the concentration of VOCs in a standard room was modeled to assess Human health risk for all six types of materials.

\section{Materials}

The internal used standards were from ethylacetate, toluene, hexanal, $n$-butyl acetate, ethylbenzene, $m, p$-xylene, styrene, $o$-xylene, $\alpha$-pinene, 3 -ethyltoluene, $D$-10-o-xylene, 1,2,4-trimethylbenzene (Supelco, Sigma Aldrich), 3- $\delta$-carene and butoxyethanol (Fluka). The parameters of samples tested for VOC content can be found in Table 1 . The size of the measured sample was $0.65 \mathrm{~m} \times 0.65 \mathrm{~m} \times 0.05 \mathrm{~m}, \mathrm{~S}=0.98 \mathrm{~m}^{3}$.

\section{Methodology}

3.1. Sampling of Released VOCs. Prior to VOC measurement, each sample was air-conditioned for $72 \mathrm{~h}$ by placing it in a small-space emission chamber. The concentration of VOCs released was assessed at different intervals of time using ISO 16000-9, (2006) standards [19]. Foam samples were placed in a hermetically sealed space of defined temperature $23^{\circ} \mathrm{C}$, relative atmospheric humidity of $50 \%$, and air velocity of 0.1 to $0.3 \mathrm{~ms}^{-1}$. Sampling for analysis was collected using a small volume space chamber VOC TEST 1000 with a volume of $1 \mathrm{~m}^{3}$. The sampling was carried out via a splitter by pumping air through two pumps with an airflow of $121 . \mathrm{h}^{-1}$ through two sorption tubes with Tenax TA sorbent, where the organic components were adsorbed on the sorbent. The time of one sampling was $180 \mathrm{~min}$. Measurement of the individual polymeric foam materials loaded with emissions for the analysis of TVOC and VOC was performed by a $24 \mathrm{~h}, 48 \mathrm{~h}$, $72 \mathrm{~h}$, and $672 \mathrm{~h}$ (28 days) intervals.

3.2. GC-MS System and Analysis of Samples. The samples collected in Tenax Tube were subjected to thermal desorption system, from where they were injected into Gas Chromatography with a mass spectrometry system equipped with the ChemStation program. The content of the sorption sampling tube is desorbed using thermal desorption from the tube into a column of capillary column gas-chromatograph and a mass-spectrometer detector (Figure 1). Subsequently, qualitative and quantitative data are evaluated using ChemStation software. The internal standard D10-o-xylene method is used for evaluation according to ISO 16000-6, (2011) [20]. The MS-SPL-BOTH method (MS-mass spectrometry, SPL-Splitless Injection Method; BOTH-collection of all ions SCAN (scanning all ions within a given weight range) and selected ions SIM (single for selected ion monitoring) in the spectrum), which works in two modes simultaneously SCAN and SIM, was used to analyze samples of air samples of tested materials (Table 2). The RT retention time, target ion $\mathrm{Tg}$ and control ions Q1, Q2, and Q3 in SIM mode are used to identify individual VOCs. The target ion peak areas ( $\mathrm{Tg}$ ) are designed to evaluate the concentration of individual VOCs. The peak 


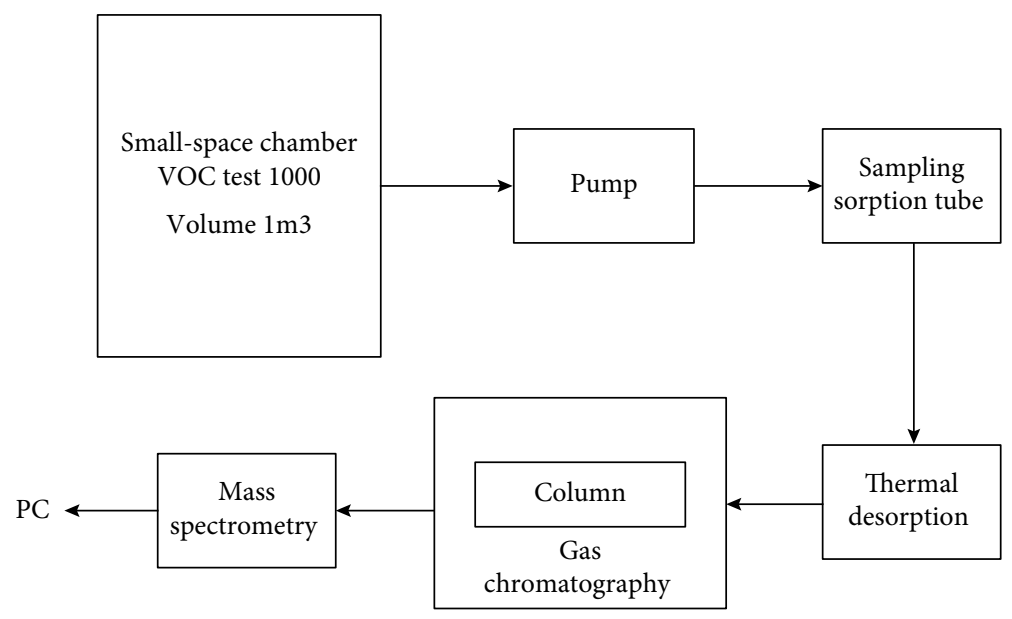

FIGURE 1: Flow chart of the various steps in VOC measurements.

areas in the total ionic ion chromatogram (TIC) are used to evaluate the TVOC. Calculate the content of VOCs and TVOC first by using ChemStation software, where we obtain the amount of analyte in ng per tube. Conversion to weight concentration is performed in Excel. The SCAN mode serves to evaluate the TVOC parameter. TVOC is the sum of all VOC compounds that are eluted from the chromatographic column between $n$-hexane and $n$-hexadecane including these.

3.3. Estimations of Human Health Risk. To assess human health risk, the worst scenario was modeled using the measured values of VOCs. The worst scenario was based on the maximum measured concentration of the compound irrespective of the time. Previously reported equations and methodology were used to assess the health risk in s standard room. These estimated values were then compared with the value of the NOAEL and PEL (if available). This gave an idea of health risk possibilities in a standard room. Upholstered furniture (modular sofa) with total surface area $12.81 \mathrm{~m}^{2}$ was assumed to be placed in a standard room of volume $30 \mathrm{~m}^{3}$. All surfaces were assumed to be emitting the VOCs to model the worst scenario. Following equations were used for modeling purpose as reported by Hillier et al. [18].

$\left(A_{\mathrm{s}}: A_{\mathrm{k}}\right)$ : area of sample in standard room and chamber, $12.81 \mathrm{~m}^{2}-0.98 \mathrm{~m}^{2}$

$\left(V_{\mathrm{s}}: V_{\mathrm{k}}\right):$ volume of standard room and chamber, $30 \mathrm{~m}^{3}-1 \mathrm{~m}^{3}$

$\left(n_{\mathrm{s}}: n_{\mathrm{k}}\right):$ air change in standard room and chamber, $0.5 \mathrm{~h}^{-1}-1 \mathrm{~h}^{-1}$

$\left(L_{\mathrm{s}}: L_{\mathrm{k}}\right)$ : area specific volume flow in a standard room and chamber, $L=A / V$

$C_{s} \quad$ calculated the concentration of the volatile chemical in a standard room

$C_{\mathrm{k}} \quad$ measured the concentration of a volatile chemical in the test chamber

$$
\begin{gathered}
C_{s}=C_{\mathrm{k}} \times\left(n_{k} / n_{s}\right) \times\left(A_{s} / A_{k}\right) \times\left(V_{k} / V_{s}\right), \\
C_{\mathrm{s}}=C_{\mathrm{k}} \times(1 / 0.5) \times(12.81 / 0.98) \times(1 / 30), \\
C_{s}=C_{k} \times(2) \times(13.07) \times(0.0333),
\end{gathered}
$$

$$
C_{s}=C_{k} \times 0.87 \text {. }
$$

Thus, the concentration of volatile chemical in a standard room is the product of concentration of volatile chemical in the test chamber multiplied by 0.87 .

\section{Results and Discussions}

The sources of VOCs in the indoor environment can be paints, furniture, appliances and decorative item. There are three levels of this problem handling source, ventilation, and air cleaning. Several methods have been reported to control VOCs in the indoor environment such as toluene adsorption using activated carbon $[15,23]$, catalytic or UV methods [22], an additive in foam formulation [17], thermal oxidation, and bio-treatment $[13,14]$ methods. Every method comes with its advantages and limitations that should be considered based on individual indoor conditions. However, this manuscript is focused on polymeric foams and health risk assessment in indoor condition by their emitted VOCs. The measured TVOC values for individual materials are presented in Figure 2. It can be seen in Figure 2 that the TVOC values were observed to be relatively high for K5040, V5020, and foam rubber materials as compared to the others. However, a time-dependent decrease in TVOC content was not observed in all materials. It also suggests the role of secondary emission and its variation based on the material properties (porosity and permeability). Additionally, the presented results indicate that the values of TVOC for K5040, N5063, and foam rubber decreased over time. While, KF 5560, R100, and V5020 behaved differently over time and did not confirm a decrease in TVOC over time. In KF5560, we can see a gradual small increase in TVOC over time, up to $72 \mathrm{~h}\left(241 \mu \mathrm{g} \mathrm{m}^{-3}\right)$, which after $672 \mathrm{~h}$ dropped sharply to $109 \mu \mathrm{g} \mathrm{m}^{-3}$. Similarly, the TVOC values for V5020 gradually increased to the $326 \mu \mathrm{g} \mathrm{m}^{-3}$ in $48 \mathrm{~h}$, followed by a negligible decrease to $323 \mu \mathrm{g} \mathrm{m}^{-3}$ in 72 and ultimately decreasing to $138 \mu \mathrm{g} \mathrm{m}^{-3}$ in $672 \mathrm{~h}$. The R100 material showed a decrease in TVOC values upto $102 \mu \mathrm{g} \mathrm{m}^{-3}$ in $72 \mathrm{~h}$. However, post $672 \mathrm{~h}$, the value is increased to $148 \mu \mathrm{g} \mathrm{m}^{-3}$. It is where the role of 
TABLE 2: Thermal desorption and GC-MS parameters used in the study.

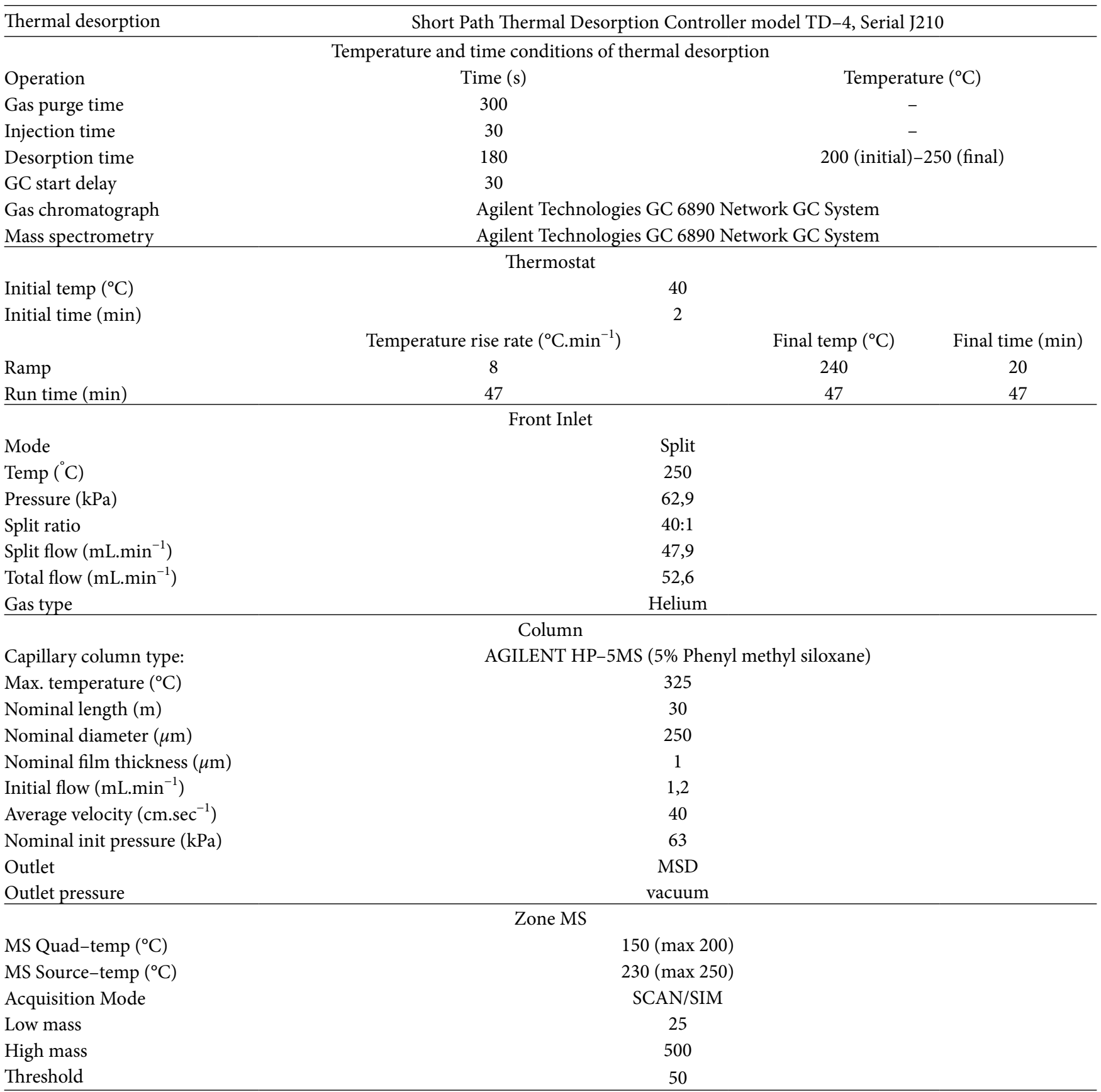

secondary emissions can be assumed to cause anomalous behaviour.

In post-24-hour measurements, all materials showed TVOC above $300 \mu \mathrm{g} \mathrm{m}^{-3}$, except for KF5560 at $180 \mu \mathrm{g} \mathrm{m}^{-3}$. The highest concentrations were measured after $24 \mathrm{~h}$ for K5040, N5063, foam rubber and R100 foamed polyurethane foams. The viscoelastic foam V5020 reached the highest concentration of $323 \mathrm{\mu g} \mathrm{m}^{-3}$ and the polyurethane foam with flame-retardants KF5560 reached the highest concentration of $216 \mu \mathrm{g} \mathrm{m}^{-3}$ for $48 \mathrm{~h}$ measurements. The highest concentration after $72 \mathrm{~h}$ was observed for viscoelastic foam V5020 $\left(323 \mu \mathrm{g} \mathrm{m}^{-3}\right)$. For K5040, KF5560, foam rubber, the concentration for $72 \mathrm{~h}$ ranged from 211 to $256 \mu \mathrm{g} \mathrm{m}^{-3}$. The lowest concentration values after $72 \mathrm{~h}$ were measured in the bound polyurethane foam R100 $102 \mu \mathrm{g} \mathrm{m}^{-3}$ and polyurethane foam $\mathrm{N} 5063124 \mu \mathrm{g} \mathrm{m}^{-3}$. The lowest concentration of $97 \mu \mathrm{g} \mathrm{m}^{-3}$ after $672 \mathrm{~h}$ was found in N5063. The highest concentration of $229 \mu \mathrm{g} \mathrm{m}^{-3}$ after $672 \mathrm{~h}$ was detected in K5040. In the case of the arithmetic mean of the TVOCs found over a total period of measurement time for the materials, we can divide these materials into three groups according to the average result value. The first group is materials that released over time over 


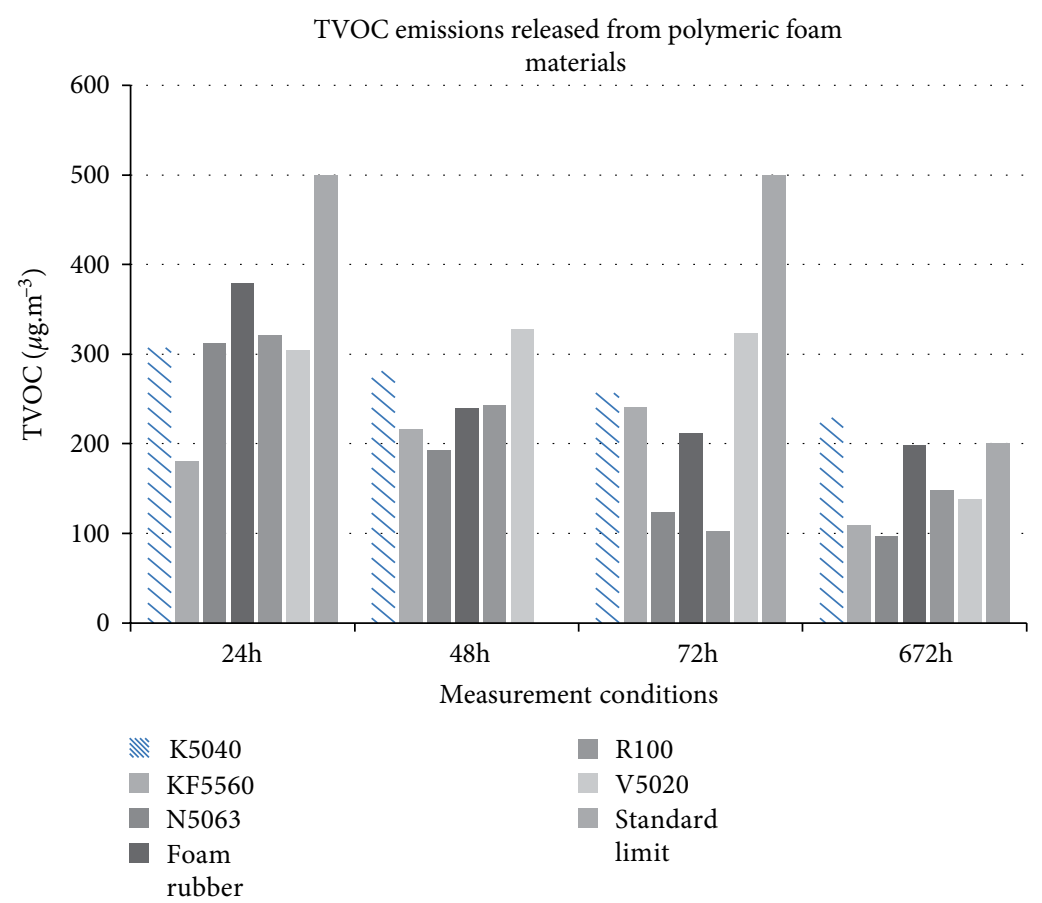

FIGURE 2: Measured TVOC concentrations for different foams with respect to time. (standard limits as per [21, 22], limits for $48 \mathrm{~h}$ not available)

$100 \mu \mathrm{g} \mathrm{m}^{-3}$ TVOC is $\mathrm{K} 5040$ and $\mathrm{R} 100$. The second group is materials that have released TVOC over $90 \mu \mathrm{g} \mathrm{m}^{-3}$, is foam rubber, N5063 and V5020 over time. Moreover, the third group is materials that released TVOC below $90 \mu \mathrm{g} \mathrm{m}^{-3}$ is KF5560 over time.

In the analysis of the identified VOCs, 13 significant substances were measured as presented in Figure 3. The highest concentration of the monitored determinant was observed for toluene $\left(26.6 \mu \mathrm{g} \mathrm{m}^{-3}\right)$ in the bound polyurethane foam R100 for $24 \mathrm{~h}$ measurements. Significant concentrations of $18 \mu \mathrm{g} \mathrm{m}^{-3}$ were also measured with foam rubber for $24 \mathrm{~h}$. The toluene was found to be in a higher concentration for all materials as compared to other substances. The lowest concentration of $3 \mu \mathrm{g} \mathrm{m}^{-3}$ after $24 \mathrm{~h}$ was detected in the viscoelastic foam V5020. The least loaded material with toluene is the viscoelastic foam V5020. The most burdened material with toluene is the bonded polyurethane foam R100. Individual concentrations of toluene gradually decrease concerning time for all measured materials.

Another compound that showed a high concentration of $19.3 \mu \mathrm{g} \mathrm{m}^{-3}$ in foam rubber and $17.8 \mu \mathrm{g} \mathrm{m}^{-3}$ in the bound polyurethane foam R100 after $24 \mathrm{~h}$ was $m, p$-xylene. The lowest concentration of $8.9 \mu \mathrm{g} \mathrm{m}^{-3}$ over $24 \mathrm{~h}$ was detected in the viscoelastic foam V5020. Although $m, p$-xylene has not reached as high concentrations as toluene in the individual foam analysis, it has, compared to other high concentrations over time, individual materials over time. The $m$ - $p$-xylene was released in minimum quantity by the V5020 viscoelastic foam. The most releasing material for $p$-xylene was a bonded polyurethane foam R100. Concentrations of $m, p$-xylene gradually decrease over time in all measured materials. The substance ethyl acetate was detected in a higher concentration above
$1 \mu \mathrm{g} \mathrm{m}^{-3}$ only in the bound R100 foam polyurethane foam. Hexanal was the most representative of K5040 polyurethane foam over time; the highest concentration reached $672 \mathrm{~h}$. Hexanal not only reduces but also increases as observed in K5040 polyurethane foam, foam rubber, and bonded R100 polyurethane foam.

$\mathrm{N}$-Butyl acetate showed the highest concentrations in foam rubber and the R100 polyurethane foam after $672 \mathrm{~h}$ and therefore did not decrease with time; this also can be attributed to secondary emissions. Ethylbenzene reached the highest concentration of $10.7 \mu \mathrm{g} \mathrm{m}^{-3}$ in the $\mathrm{N} 5063$ polyurethane foam after $24 \mathrm{~h}$, with concentrations lower than $1 \mu \mathrm{g} \mathrm{m}^{-3}$ after $48 \mathrm{~h}-672 \mathrm{~h}$. It was significantly accentuated with time for K5040 polyurethane foam, foam rubber and bonded R100 polyurethane foam. The concentration of styrene was observed to be decreasing with time for K5040 polyurethane foam, foam rubber, and bonded R100 polyurethane foam. $O$-xylene showed the highest concentration of $8.3 \mu \mathrm{g} \mathrm{m}^{-3}$ in foam rubber after $24 \mathrm{~h}$. It was followed by a decrease with time. A similar trend was observed in all other samples too, except viscoelastic foam V5020. O-xylene concentration showed a decrease over time for all types of tested samples. For butoxyethanol, the highest concentration reached $3.6 \mu \mathrm{g} \mathrm{m}^{-3}$ in foam rubber for $672 \mathrm{~h}$. No decrease in concentration was observed with time. $3-\delta$-Caren at was measured above $1 \mu \mathrm{g} \mathrm{m}^{-3}$ after $24 \mathrm{~h}, 48 \mathrm{~h}, 72 \mathrm{~h}$, and $672 \mathrm{~h}$ in foam rubber only. The highest concentration was reached after $72 \mathrm{~h}$.

None of the measured TVOC values of individual materials exceeded the Ecolabel and CertiPUR label requirements, where the concentration of volatile organic compounds should not exceed $500 \mu \mathrm{g} \mathrm{m}^{-3}$. In the simulated health risk assessment, none of the compounds showed a value higher than prescribed 


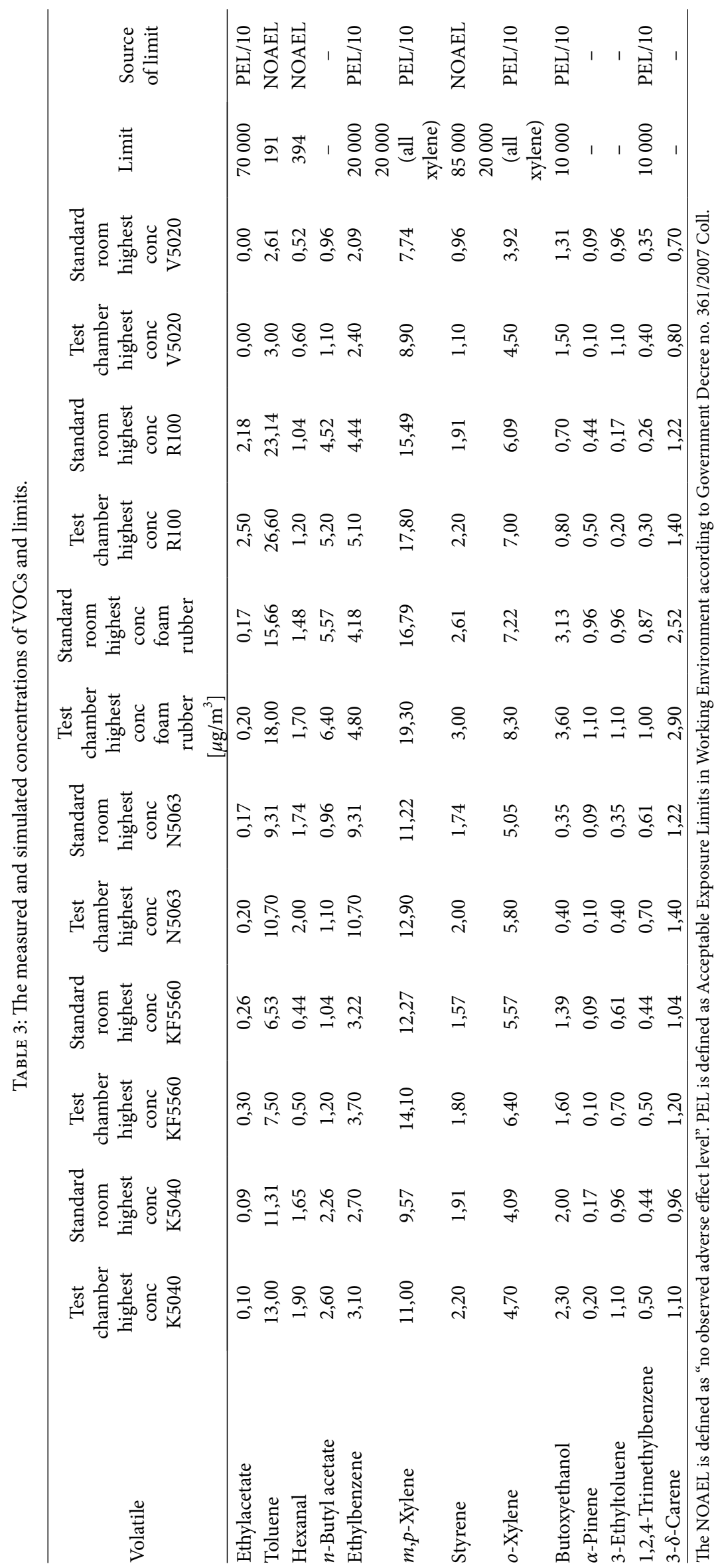




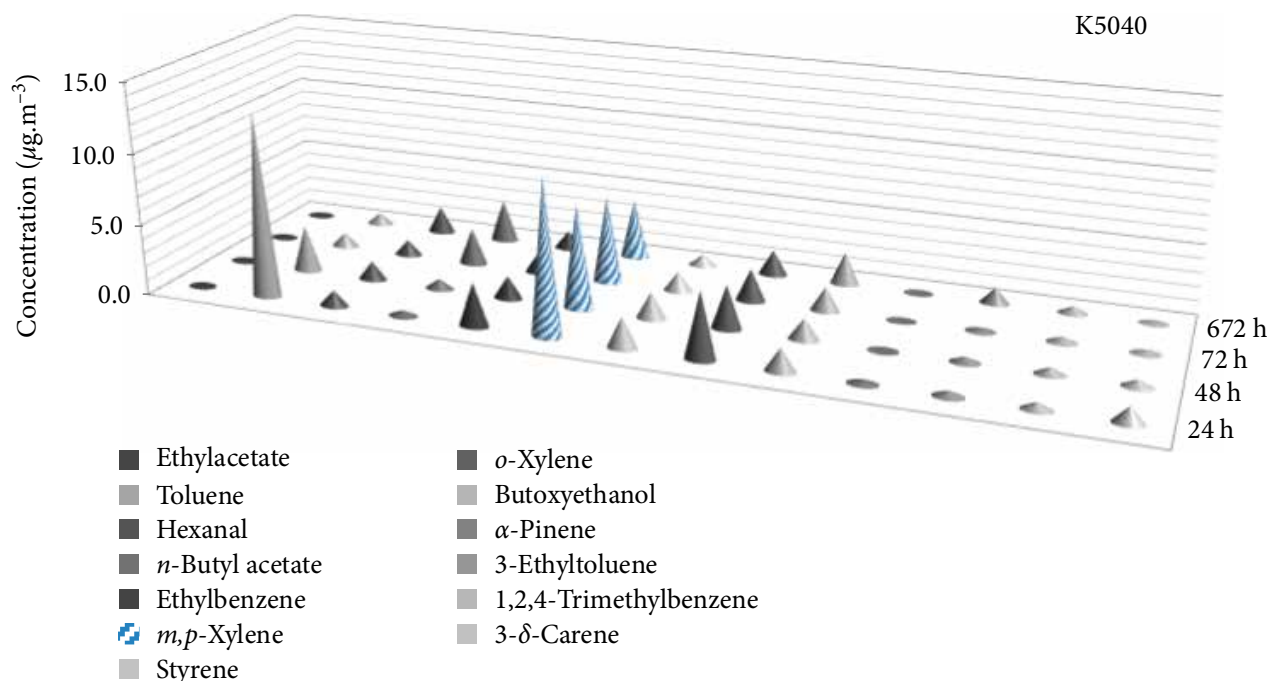

(a)

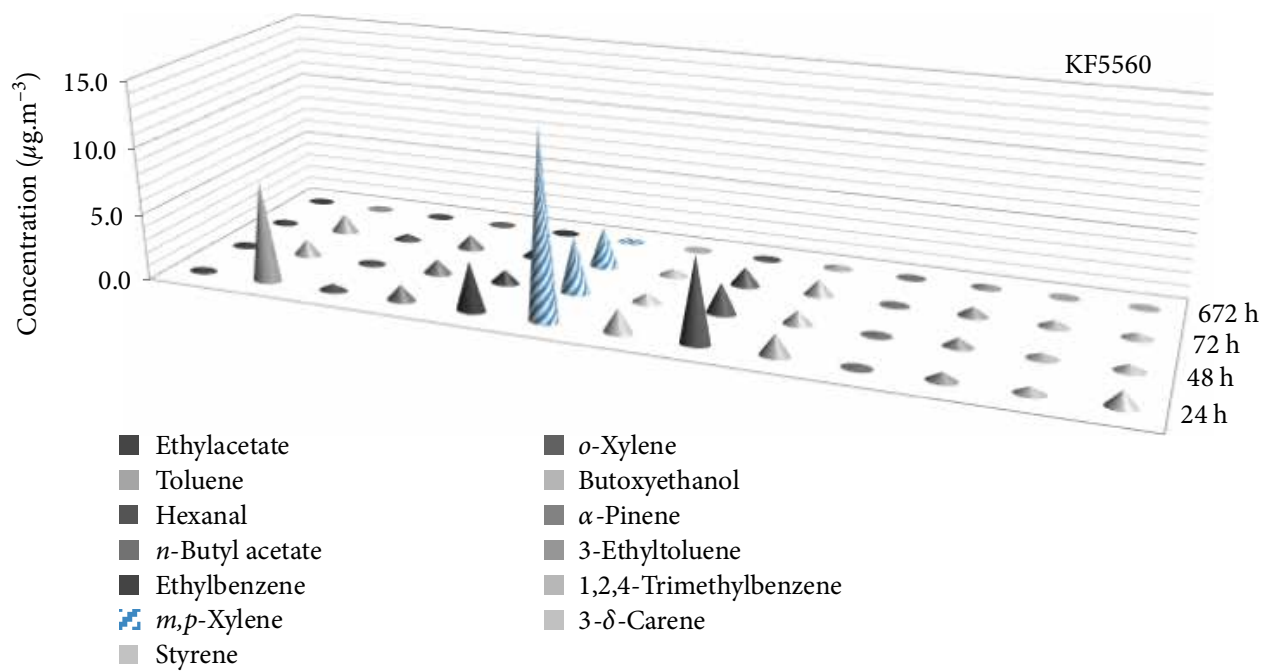

(b)

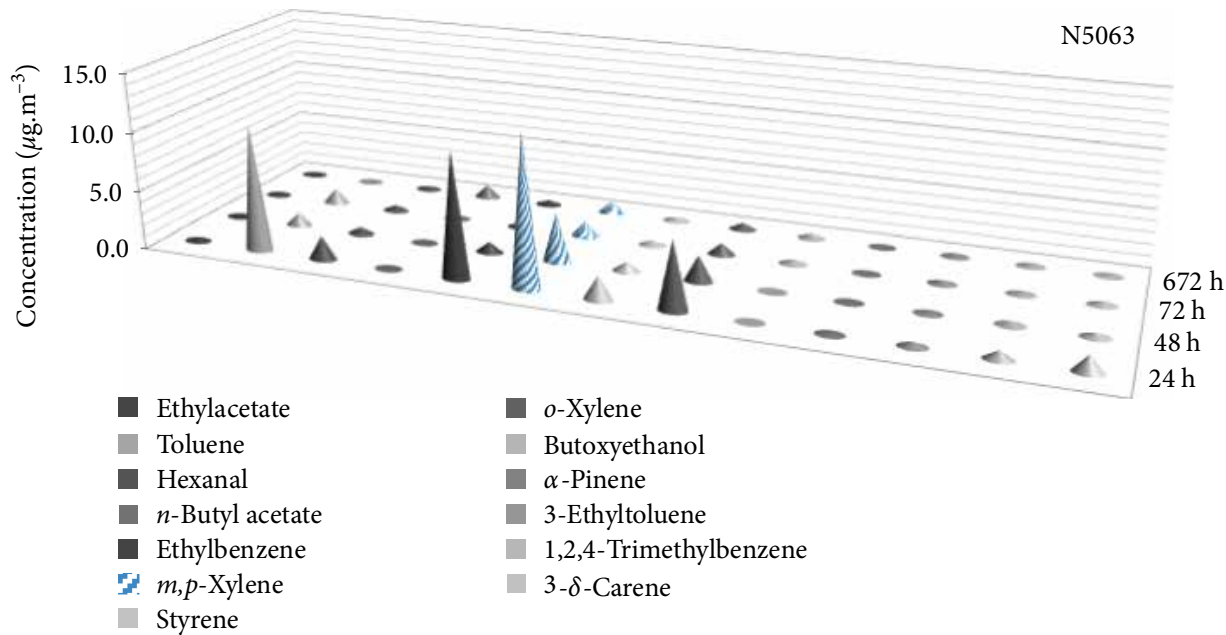

(c)

FIgUre 3: Continued. 


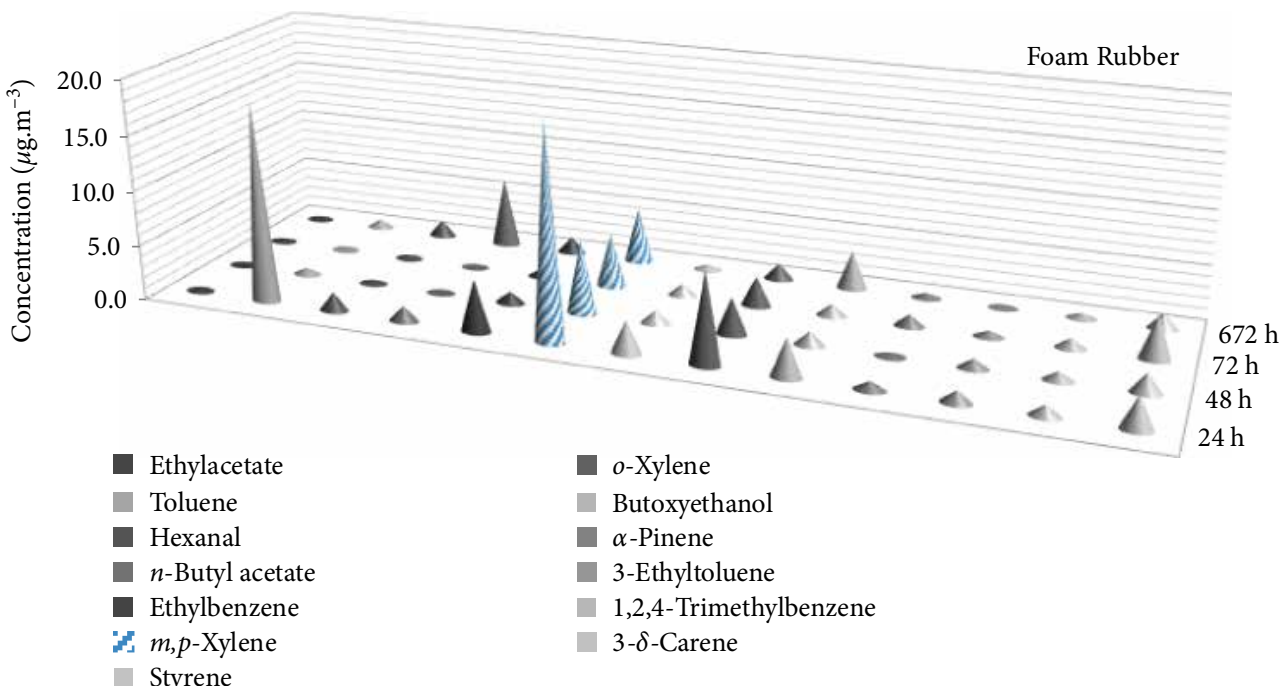

(d)

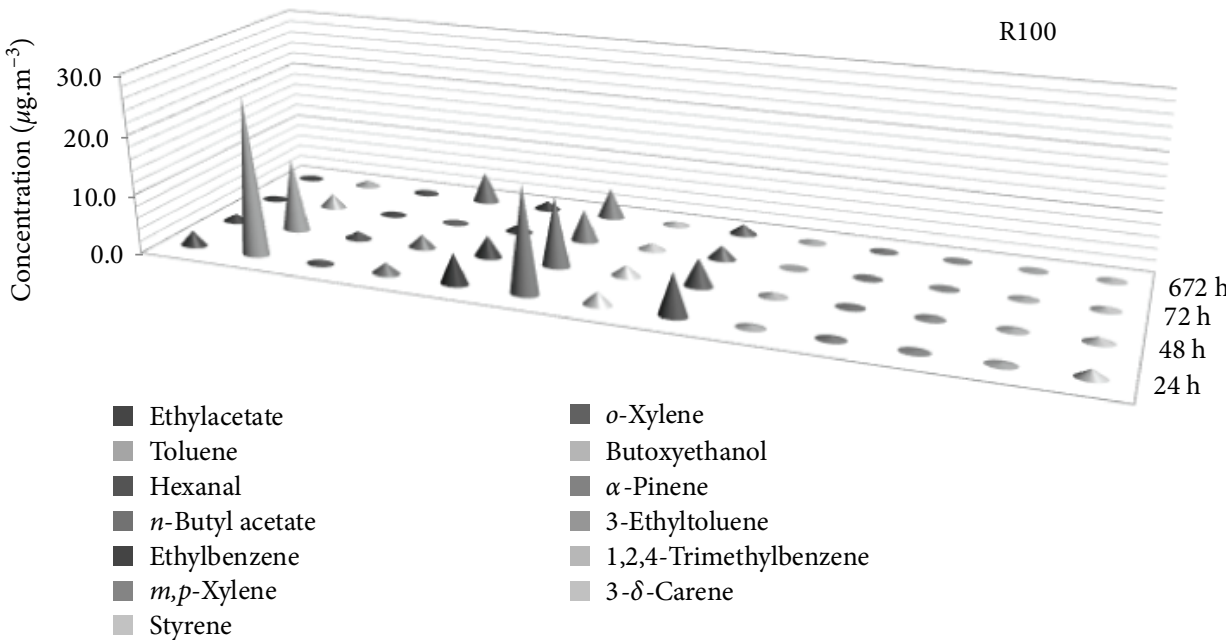

(e)

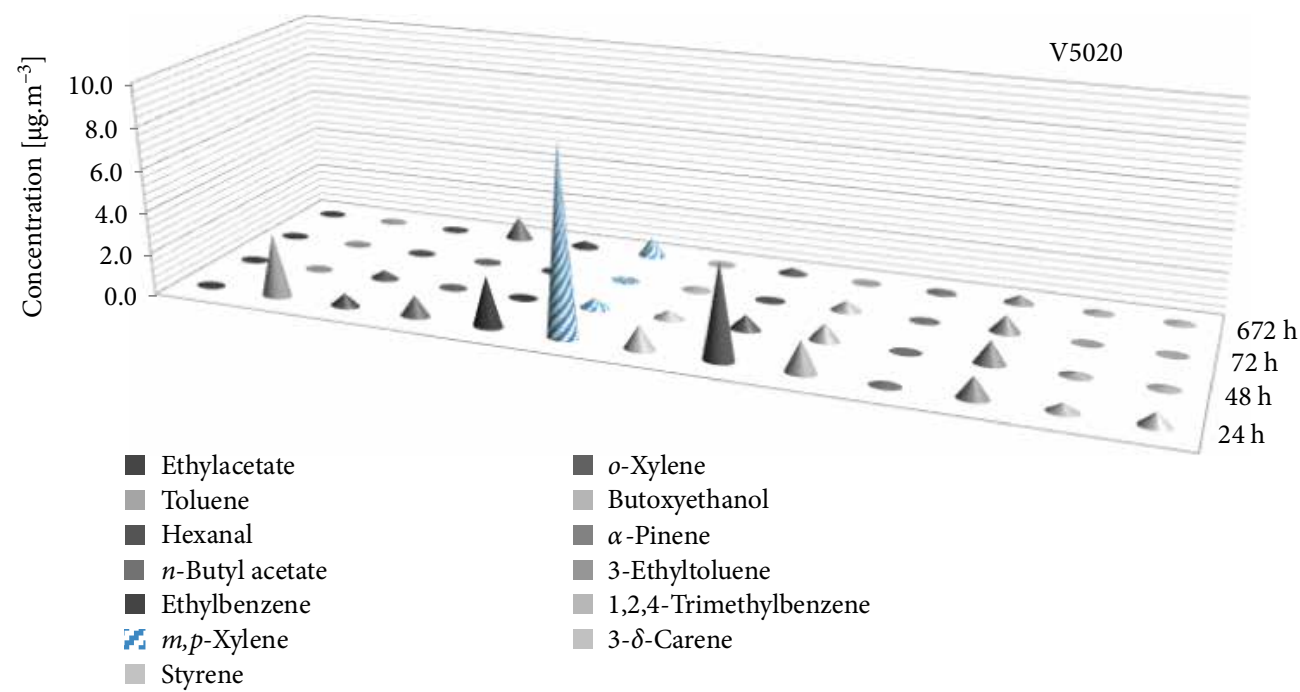

(f)

FIgURE 3: Concentration of Different VOCs emitted by different foams with time. 
limits; thereby no health risk could be suggested (Table 3 ). The maximum simulated value was observed for Toluene in R100 with $23.14 \mu \mathrm{g} / \mathrm{m}^{3}$ that too was much below the prescribed values by NOEL.

\section{Conclusion}

VOCs are released from materials in different ways over time. Therefore, we can not say that in time the concentration decreases if we take the order of the individual measurements after $24 \mathrm{~h}, 48 \mathrm{~h}, 72 \mathrm{~h}$, and $672 \mathrm{~h}$ in the determined VOCs or the peak area decreases for the identified VOCs. As a result, the values after $672 \mathrm{~h}$ are much lower than after $24 \mathrm{~h}$. However, not for all measured materials, we can see that the concentration of the VOC peak would be lower than the initial 24-hour measured concentration. Thus, over a longer period, the concentration or peak area decreases compared to the initial measurement. In the case of individual polymeric foam materials, the comparison of the concentrations in the decreasing order, ethylacetate, toluene, hexanal, $n$-butylacetate, ethylbenzene, $m, p$-xylene, styrene, $o$-xylene, butoxyethanol, 3-ethyltoluene, 1,2,4-trimethylbenzene, 3- $\delta$-carene. As observed, the comparison of the peak area, the decreasing order follows as, 1,4-dimethylpiperazine, 4-ethylmorpholine, triethylenediamine, N,N-dimethylbenzene-methanamine, undecane, 2-ethylhexanoic acid, decamethylcyclo-pentasiloxane, dodecane, tridecane, and dodecamethylcyclohexasiloxane.

It can be concluded that it is difficult to generalize the time-dependent decrease in VOC release with time for all kind of polymers as these values vary on time, material, and individual VOC basis. However, in simulated values, it can be seen that none of the studied VOCs was observed to be even near the prescribed limit. Hence zero health risk can be suggested. Considering the variation in source dependent nature and quantity of TVOC cocktail and in toxicity level of individual compound, it is suggested to minimise their content at different possible levels. Various formulation strategies for foams with functional additives in addition to the modified fabrics should be utilised to minimise VOC emissions.

\section{Data Availability}

The datasets generated during and/or analyzed during the current study are available from the corresponding author on reasonable request.

\section{Conflicts of Interest}

The authors declare that they have no conflicts of interest.

\section{Acknowledgments}

The authors are grateful for the support of the Technology Agency of Czech Republic; grant number TH03030416 through the project "Progresivní konstrukce a řízení sušáren pro těžko sušitelné dřeviny včetně exotických” for the financial support.

\section{References}

[1] P. Pluschke and H. Schleibinger, Indoor Air Pollution - Part F, Springer, Spain, 2018, https://www.springer.com/gb/ book/9783662560631.

[2] D. Tesarova, P. Cech, E. Jeřábková et al., "Effect of ethylene oxide sterilization and accelerated ageing on the physical and mechanical properties of beech, oak, and elm wood: part 2," BioResources, vol. 13, no. 4, 2018.

[3] D. Tesařová, A. Capíková, E. Jeřábková, P. Čech, A. Ekielski, and P. K. Mishra, "Effect of ethylene oxide sterilization and accelerated ageing on the physical and mechanical properties of beech, oak, and elm wood: part 1," BioResources, vol. 13, no. 4, 2018.

[4] D. A. Sarigiannis, S. P. Karakitsios, A. Gotti, I. L. Liakos, and A. Katsoyiannis, "Exposure to major volatile organic compounds and carbonyls in European indoor environments and associated health risk," Environmental International, vol. 37, no. 4, pp. 743-765, 2011.

[5] H. Mishra, P. K. Mishra, A. Ekielski, M. Jaggi, Z. Iqbal, and S. Talegaonkar, "Melanoma treatment: from conventional to nanotechnology," Journal of Cancer Research and Clinical Oncology, vol. 144, no. 12, pp. 2283-2302, 2018.

[6] P. K. Mishra, K. Giagli, D. Tsalagkas et al., "Changing face of wood science in modern era: contribution of nanotechnology," Recent Patents Nanotechnology, vol. 12, no. 1, pp. 13-21, 2018.

[7] P. K. Mishra and A. Ekielski, "The self-assembly of lignin and its application in nanoparticle synthesis: a short review," Nanomaterials, vol. 9, no. 2, p. 243, 2019.

[8] P. K. Mishra and R. Wimmer, "Aerosol assisted self-assembly as a route to synthesize solid and hollow spherical lignin colloids and its utilization in layer by layer deposition," Ultrasonics Sonochemistry, vol. 35, pp. 45-50, 2017.

[9] J. Bhandari, H. Mishra, P. K. Mishra, R. W. Wimmer, F. J. Ahmad, and S. Talegaonkar, "Cellulose nanofiber aerogel as a promising biomaterial for customized oral drug delivery," International Journal of Nanomedicine, vol. 12, pp. 2021-2031, 2017.

[10] P. K. Mishra and A. Ekielski, "A simple method to synthesize lignin nanoparticles," Colloids and Interfaces, vol. 3, no. 2, p. 52, 2019.

[11] J. Laverge, A. Novoselac, R. Corsi, and A. Janssens, "Experimental assessment of exposure to gaseous pollutants from mattresses and pillows while asleep," Building and Environment, vol. 59, pp. 203-210, 2013.

[12] Y. Huang, S. S. H. Ho, Y. Lu et al., "Removal of indoor volatile organic compounds via photocatalytic oxidation: a short review and prospect," Molecules, vol. 21, no. 1, p. 56, 2016.

[13] S. Lau, K. Groody, A. Chan, and G. Ragib, "Control of reduced sulphur and VOC emissions via biofiltration," Pulp and Paper Research journal, vol. 107, pp. 57-63, 2006.

[14] T. P. Kumar, M. Rahul, and B. Chandrajit, "Biofiltration of volatile organic compounds (VOCs): an overview," Research Journal of Chemical Science, vol. 2231, p. 606X, 2011.

[15] A. Mofidi, H. Asilian, and A. J. Jafari, "Adsorption of volatile organic compounds on fluidized activated carbon bed," Health Scope, vol. 2, pp. 84-89, 2013.

[16] N. Adam, G. Avar, H. Blankenheim et al., "Polyurethane," Ullmann's Encyclopedia of Industrial Chemistry, 2005.

[17] J. J. Burdeniuc, J. D. Tobias, and R. J. Keller, "Process for producing flexible polyurethane foam using natural oil polyols," 2012, Patent EP12735726.7A. 
[18] K. Hillier, T. Schupp, and I. Carney, "An investigation into VOC emissions from polyurethane flexible foam mattresses," Cellular Polymers, vol. 22, no. 4, pp. 237-259, 2003.

[19] ISO 16000-9, Indoor Air-Part 9: Determination of the Emission of Volatile Organic Compounds from Building Products and Furnishing-Emission Test Chamber Method, International Organization for Standardization, 2006.

[20] ISO 16000-6, Indoor Air-Part 6: Determination of Volatile Organic Compounds in Indoor and Test Chamber Air by Active Sampling on Tenax TA Sorbent, Thermal Desorption and Gas Chromatography Using MS/FID, International Organization for Standardization, 2011.

[21] B. Guieysse, C. Hort, V. Platel, R. Munoz, M. Ondarts, and S. Revah, "Biological treatment of indoor air for VOC removal: potential and challenges," Biotechnology Advances, vol. 26, no. 5, pp. 398-410, 2008.

[22] S. Wang, H. M. Ang, and M. O. Tade, "Volatile organic compounds in indoor environment and photocatalytic oxidation: state of the art," Environment International, vol. 33, no. 5, pp. 694-705, 2007.

[23] M. P. Cal, M. J. Rood, and S. M. Larson, "Removal of VOCs from humidified gas streams using activated carbon cloth," Gas Separation \& Purification, vol. 10, no. 2, pp. 117-121, 1996. 


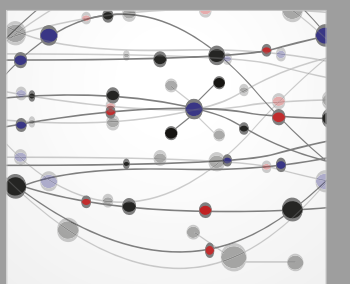

The Scientific World Journal
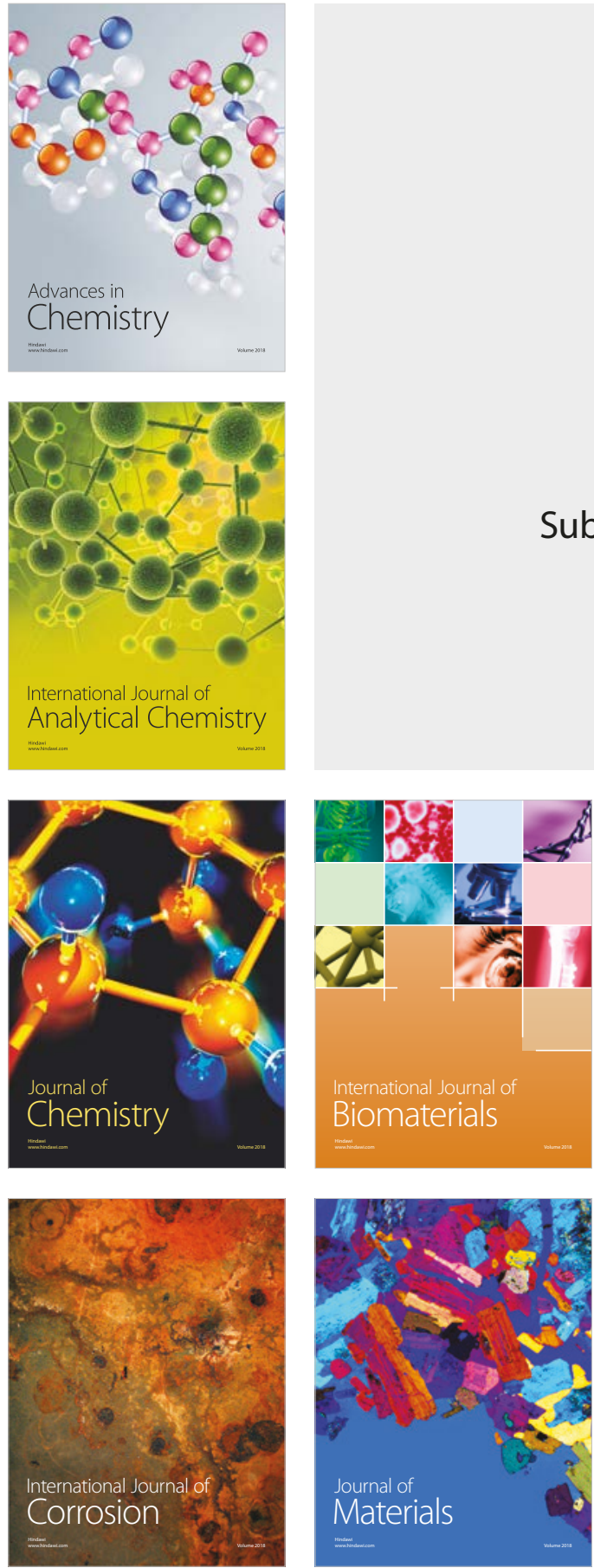

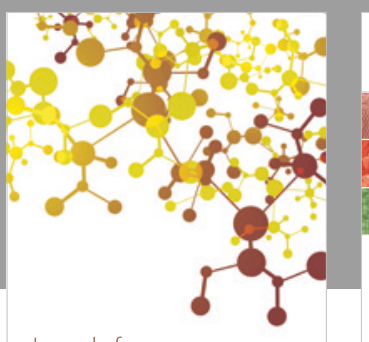

Journal of

Applied Chemistry
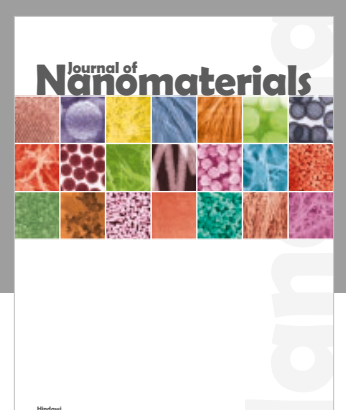

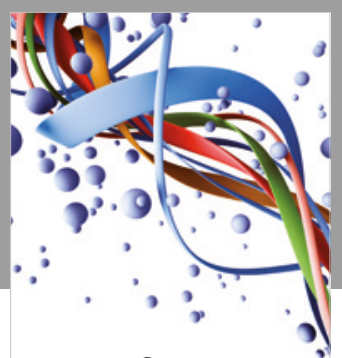

Scientifica

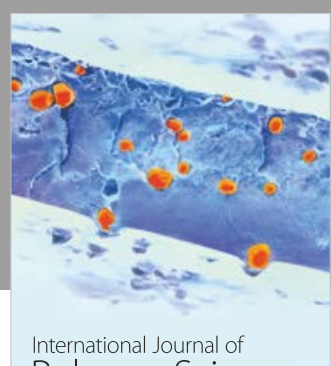

Polymer Science

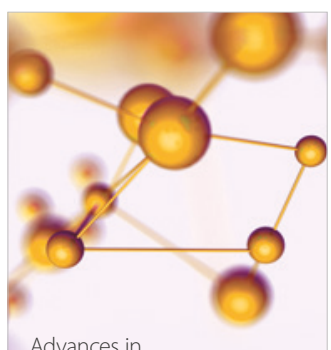

Physical Chemistry
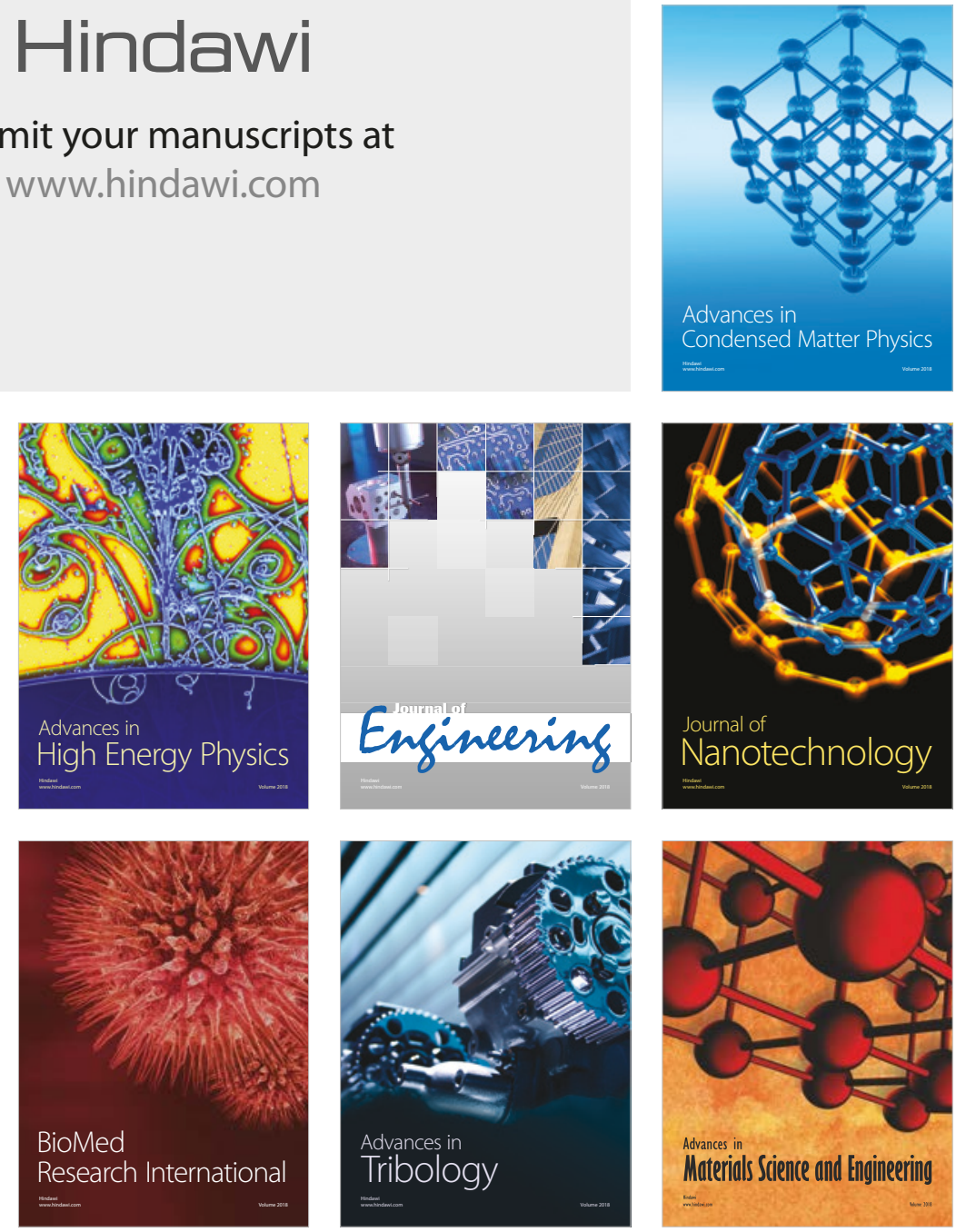